\title{
対流が存在する飽和多孔質体における凝固特性* （冷却面温度变動に対する固液界面位置の応答）
}

木 村 繁 男*1, 岡 島 厚*2
木 綿 隆 弘*2, 房 岡高広*3

Solidification in a Water-Saturated Porous Medium When Convection is Present

(Response of the Solid-Liquid Interface to the Cooling Temperature Fluctuation)

Shigeo KIMURA*4, Atsushi OKAJIMA, Takahiro KIWATA and Takahiro FUSAOKA

${ }^{* 4}$ Inst. of Nature and Environmental Technology,

2-40-20 Kodatsuno, Kanazawa-shi, Ishikawa, 920-8667 Japan

\begin{abstract}
Fundamental study on a solidifying phenomenon in a rectangular water-saturated porous medium was carried out when vigorous convection occupies the liquid layer. The system is cooled from the upper boundary and heated from below. In this study, the dynamic response of the solidliquid interface to the periodical temperature fluctuation at the cooling surface was investigated in detail. Especially, the amplitude of solid-liquid interface and the phase lag to the time-varying cooling temperature were monitored for various periods and cooling temperatures. One-dimensional numerical model was developed by assuming the constant convective heat flux from liquid regime. The numerical model explains well the observed experimental results. It is found that the amplitude of oscillating solid-liquid boundary increases in proportion to the temperature fluctuation period, and that both the thicker solid layer and the shorter period cause the greater phase lag.
\end{abstract}

Key Words: Solidification, Porous Medium, Cooling Temperature Fluctuation, Natural Convection, Numerical Analysis

\section{1. 緒 論}

凝固・融解現象は惑星科学や工学など幅広い分野で 観察される現象である．相変化を利用した蓄冷形空気 調和システムや金属の鋳造工程, 食品の冷凍など我々 の身近なところにも多く見られ，その特性の解明は極 めて重要である(1)(2). 流体で飽和した多孔質体内での

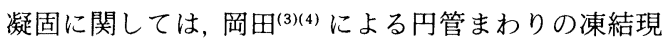
象についての解析がある。 また多孔質で満たされた矩 形空間内での凝固プロセスについては水の密度極大を 考慮した対流熱伝達率に関するSugawara ら(5)によ る実験や, 二次元数值計算により多孔質体内の凍結を 論じた Sasakiら(6)の研究がある。またViskanta ら(7)による側壁に加熱・冷却部を有する矩形水槽に おける凝固成長の実験および数値計算など多くの報告 がなされている，しかし，これまでの凝固・融解に関 する研究は, 系境界の温度を一定としているものがほ とんどであった，凝固プロセスはおもに凝固点温度と

* 原稿受付 2004 年 7 月 20 日.

*1 正員, 金沢大学自然計測応用研究センター( 沢市小立野 2-40-20)

*2 正員, 金沢大学大学院自然科学研究科.

*3 学生員, 金沢大学大学院自然科学研究科.

E-mail : skimura@t.kanazawa-u.ac.jp
冷却面温度との差や, 液相内での対流熱伝達によって 支配されるが，主要な支配的要素の一つである冷却面 温度が変動する場合に, 固液界面がどのように変化す

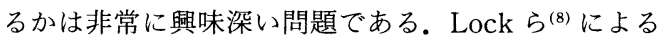
一次元半無限領域における水の周期的凝固プロセスに 関する報告があるが，本研究では飽和多孔質体におい て, 冷却面温度に時間的変動を与えた際の固相生成挙 動の動的応答特性に注目した。

多孔質層内の動的凝固プロセスが関与する現象とし て，地下水の熱を有効利用する地中熱ヒートポンプシ ステムに関するものがあげられる．すなわち地中熱交 換器周辺の地下水が凝固し，熱交換効率が低下する問 題である。地中からの抽出熱量は地上における暖房負 荷の大小により時間的に変動し,これに伴い地中熱交 換器冷却面温度が変動することになる，また，地球物 理学や環境科学の分野においては, 寒冷地の凍土厚さ の季節変動などが挙げられる(9)(10).

本研究ではこのような背景から凝固・融解現象全般 を対象とした基礎的研究として, 水で飽和した正方形 多孔質体内の水が上方から凝固点以下で冷却される場 合の固相の生成挙動について検討した，液相部に自然 対流を伴わない領域における研究が木村ら(11)によっ てなされているが, 本研究では液相部に活発な自然対 
流を伴う場合を取り上げる。冷却側の境界条件とし て, 冷却面温度に矩形波状の周期的変動を与え, 加熱 側の底面温度は凝固点以上の温度に固定した.このと き冷却面温度変動が凝固・融解過程に及ぼす影響を実 験により明らかにするとともに，一次元数值計算モデ ルを提案し, 比較的活発な対流が存在する場合の本計 算モデルの有効性について検討した。

\section{2. おもな記 号}

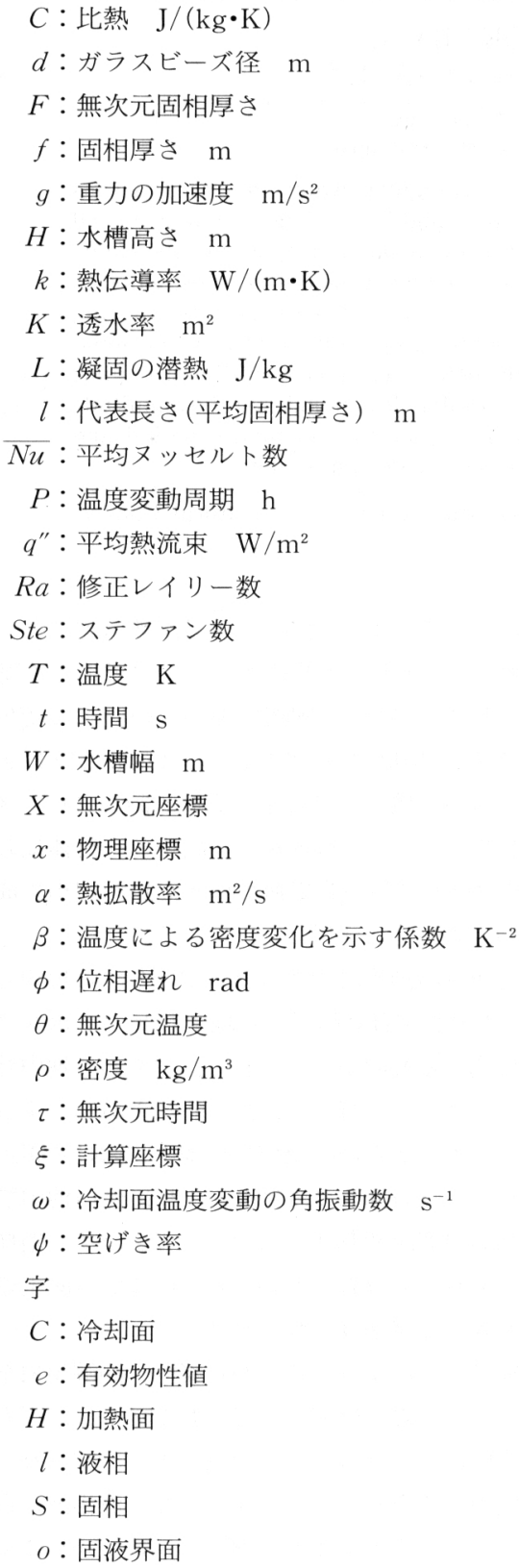

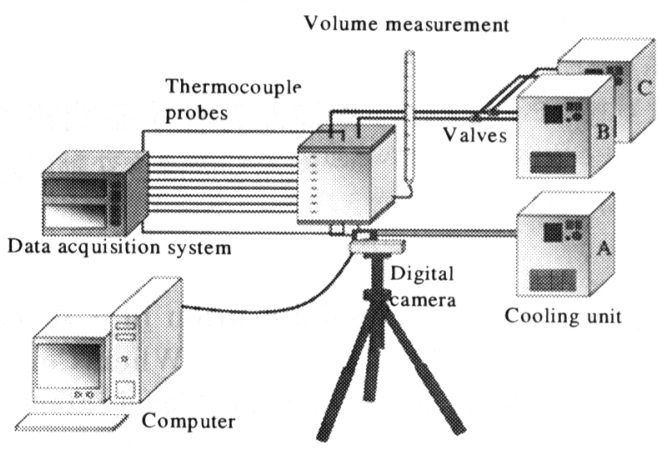

Fig. 1 Experimental apparatus

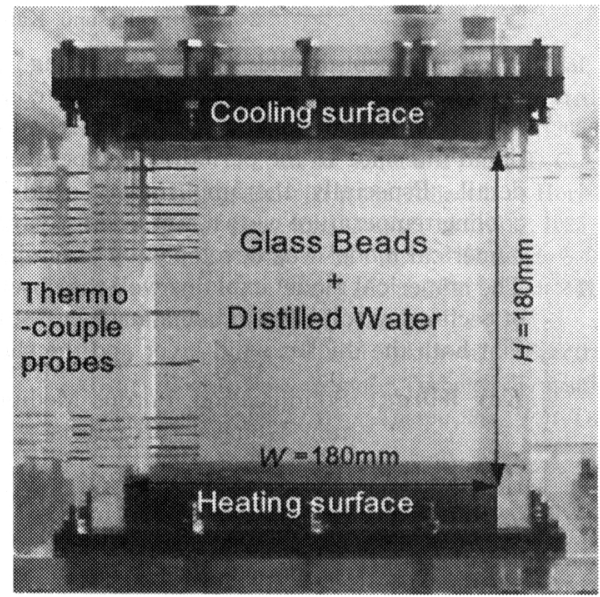

Fig. 2 Rectangular tank filled with water saturated glass beads

\section{3. 実験装置および方法}

$3 \cdot 1$ 実験装置本研究で使用した実験装置の概 略を図 1 に, 水槽の外観写真を図 2 に示す。水槽は内 側の寸法が幅 $W 180 \mathrm{~mm} \times$ 高さ $H 180 \mathrm{~mm} \times$ 奥行き $175 \mathrm{~mm}$ であり，上下面は加熱冷却用の銅板，側壁は 厚さ $15 \mathrm{~mm}$ のアクリル板でできている。水槽全体を 外側からアクリル樹脂製の箱と発泡スチロールの箱で 二重に囲み, さらに小形恒温装置により, 間の空気層 の温度を加熱面と冷却面温度の中間温度 $\left(T_{H}+T_{C}\right) / 2$ に保つことで，系全体を断熱した．水槽上下面の銅板 内部にはチャンバが設けられ，恒温冷凍装置からの一 定温度の冷媒(エチレングリコール水溶液)が循環でき るようになっている。供試多孔質体には平均直径 $d=$ $5 \mathrm{~mm}$ および $2 \mathrm{~mm}$ のガラスビーズを充てんして空間 を蒸留水で満たしたものを用いた。なお，ガラスビー ズを正方形水槽に満たした場合の空げき率の実測値は 
ほほ 0.4 であった。図 2 のように水槽内の温度分布お よび冷却面と加熱面の温度測定には合計 20 本の $\mathrm{T}$ 形 熱電対とデータロガーを使用した。

$3 \cdot 2$ 実験方法 本実験では上面銅板を冷却側, 下面銅板を加熱側とするので，固相は上面から成長す る. 初期条件として, 恒温冷凍装置 A, Bにより冷媒 を $20^{\circ} \mathrm{C}$ に保ち, 水槽内全体が一様な温度になるまで十 分な時間を置く，その後, 恒温冷凍装置 Cにより，任 意の温度に設定した冷媒を循環させ上面を冷却させ る. 冷却温度を周期的に変化させるために，もう一方 の恒温冷凍装置 B を次の目的温度に設定しておき，流 路のバルブを切換えて水槽上面の冷却面に矩形波状の 温度変動を与えた。

$3 \cdot 3$ 固相厚さの測定方法 本研究で扱った水と ガラスビーズからなる飽和多孔質体においては，固液 界面の位置を外部より目視で確認することは非常に困 難である．また，熱電対により凝固温度の場所を特定 することも過冷却の影響や設置可能な本数を考えると 適切ではない.そこで本実験では固相厚さの測定に， 水が氷に相変化する際の体積膨張変化を利用した。 まり, 水層の成長に伴い排斥される水を水槽の底板近 くの側壁細管より体積計に誘導し，空げき率，凝固に 伴う密度変化より, 生成した氷の固相厚さを算出し $た^{(5)(11)}$.

\section{4. 一次元数值解析}

一般に多次元の自然対流計算は，多くの計算時間を 要したり, 高レイリ一数領域で発散などの困難を伴う 場合が多い。ここでは，液相部の温度場および流れ場 に関する計算を省略し，対流の効果を固液界面が液相 から受ける平均の対流熱伝達量で置き換えた一次元数 值計算モデルについて述べる. 図 3 に一次元解析モデ ルの概略を示す. 液相部は固相厚さに比べ十分深く, 固相下面は自然対流熱伝達による液相からの平均熱流 束 $q^{\prime \prime}$ を受ける.また, 冷却面温度が周期的に変動し ても, 固液界面の変動振幅が液相深さに比べ十分小さ ければ, 熱流束は近似的に一定とみなすことができ る.

冷却面温度が一定で定常状態になっている場合, 固 相が液相から受ける平均熱流束と, 固相内の平均熱流 束は等しくなる．固相内温度分布は図 3 のように直線 になり，したがって固相内の熱流束は冷却面温度と固 相厚さから算出できる。これから固液界面が液相から 受ける平均熱流束 $q^{\prime \prime}$ を決定することができる，以下 に固相内のエネルギー保存式と固液界面でのエネルギ 一バランスの式を示す(12).

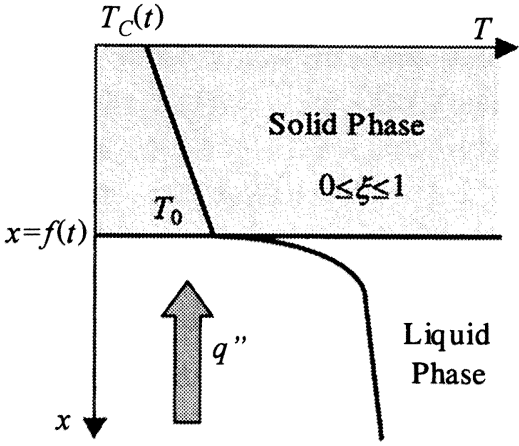

Temp. Profile

Fig. 3 One-dimensional model and the coordinate system

固相内エネルギー式：

$$
\frac{\partial T_{S}}{\partial t}=\alpha_{s} \nabla^{2} T_{S}
$$

固液界面熱平衡式：

$$
\rho_{s} \psi L \frac{\partial f}{\partial t}=\left.k_{S} \frac{\partial T_{S}}{\partial x}\right|_{x=f}-q^{\prime \prime}
$$

無次元パラメータ :

$$
\left.\begin{array}{l}
\theta_{s}=\frac{T_{s}-T_{0}}{T_{0}-\bar{T}_{C}}, X=\frac{x}{l}, F=\frac{f}{l}, \tau=\frac{\alpha_{s}}{l^{2}} t \\
l=\frac{k_{S}\left(T_{0}-\bar{T}_{C}\right)}{q^{\prime \prime}}, \text { Ste }=\frac{C_{S}\left(T_{0}-\bar{T}_{C}\right)}{\psi L}, \xi=\frac{X}{F}
\end{array}\right\}
$$

式(3)を用いて式(1)，（2）に無次元化を施し, 次の 無次元支配方程式を得る。

固相内エネルギー式：

$$
\frac{\partial \theta_{s}}{\partial \tau}=-\frac{\partial \xi}{\partial \tau} \frac{\partial \theta_{s}}{\partial \xi}+\left(\frac{\partial \xi}{\partial X}\right)^{2} \frac{\partial^{2} \theta_{s}}{\partial \xi^{2}}
$$

固液界面での熱平衡式 :

$$
\frac{\partial F}{\partial \tau}=\text { Ste }\left[\left.\left(\frac{\partial \xi}{\partial X}\right) \frac{\partial \theta_{S}}{\partial \xi}\right|_{\xi=1}-1\right]
$$

境界条件：

$$
\begin{array}{lll}
\theta_{s}=\theta(t) & \text { at } & \xi=0 \\
\theta_{S}=0 & \text { at } & \xi=1
\end{array}
$$

なお, 式 ( 3 )の温度の無次元化で $\bar{T}_{c}$ は時間平均冷 却面温度である. 移動境界の取扱いに際して, 境界固 定法(13)を適用した。また, 式(4)，(5)の離散化に は, 空間の差分近似に四次精度多点差分, 固液界面に おける温度こう配の算出には四次精度片側差分, 時間 進行法には二次精度の Adams-Bashforth 法を用い た. Adams-Bashforth 法は 3 時刻レベル法であるた め計算開始時に 2 ステップ以上時間が経過していなけ ればならない.そこで本研究では初期条件として, $\tau$ $=0.02$ におけるノイマンの厳密解より得られる固液 
界面位置と固相内温度分布を与えた.

本研究では, 実験との比較をする場合, 固相厚さか ら平均熱流束を算出したが，一般的には自然対流熱伝 達の相関式から推定することができる. 通常, 無次元 熱伝達率であるヌッセルト数はレイリー数のべき乗と いう形をもっており,レイリー数は多孔質マトリック スの透水率, 液相部厚さ, 上下面間の温度差, 飽和流 体の物性值により決定される。

飽和多孔質体の有効熱伝導率は直接測定するか, 液 体と固体の体積平均から求められる。本実験では液相 の場合は多孔質マトリックスであるガラスビーズと水 の熱伝導率から $k_{e}=(1-\psi) k_{s}+\psi k_{l}$ により計算し $k_{e l}$ $=0.83 \mathrm{~W} /(\mathrm{m} \cdot \mathrm{K})$ を得た。また, 京都電子工業 (株)の 熱伝導率計 QTM-D 3 により直接測定も実施した。 測定結果はこれより $5 \%$ ほど大きい值であった．氷層 についても同様に計算し $k_{e s}=1.50 \mathrm{~W} /(\mathrm{m} \cdot \mathrm{K})$ を得 た.

水の凝固のように $4^{\circ} \mathrm{C} に お け る$ 密度極大を伴う場合 については, Sugawaraらによる詳細な研究があ る(5).それによれば, 密度極大の影響は, 加熱側温度 が高くなると小さくなる傾向がある. したがって, 本 実験条件のように加熱面温度が $4^{\circ} \mathrm{C}$ りも比較的大き い場合は，密度極大の影響を無視した対流熱伝達の相 関式から平均熱流束を推定可能と考える.

\section{5. 実験と計算結果および考察}

$5 \cdot 1$ 冷却面温度に対する固液界面変化 定常時 の固相厚さを調べるために, 下面の加熱面温度 $T_{H}=$ $20^{\circ} \mathrm{C}$ で一定に保持し, 上面の冷却面温度 $T_{C}$ を

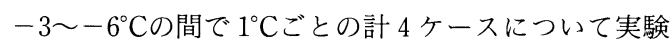

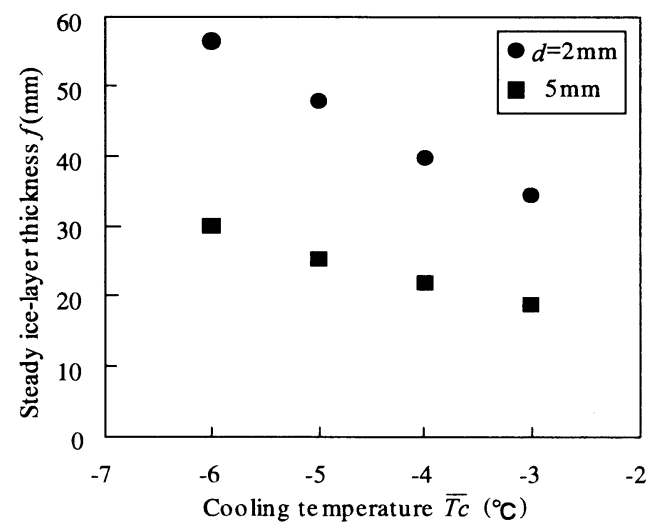

Fig. 4 Ice-layer thickness at steady state as a function of cooling temperature (The bottom temperature is fixed at $T_{H}=20^{\circ} \mathrm{C}$ )
を行った. 図 4 に冷却面温度 $T_{c}$ に対する定常時の固 相厚さを示す. 定常時の固相厚さは冷却面温度 $T_{C}$ の 低下に伴い増加し，また，ガラスビーズ径が大きい $d$ $=5 \mathrm{~mm}$ の場合のほうが対流熱伝達が活発になるた め, 固相の成長がより抑制されているのがわかる.

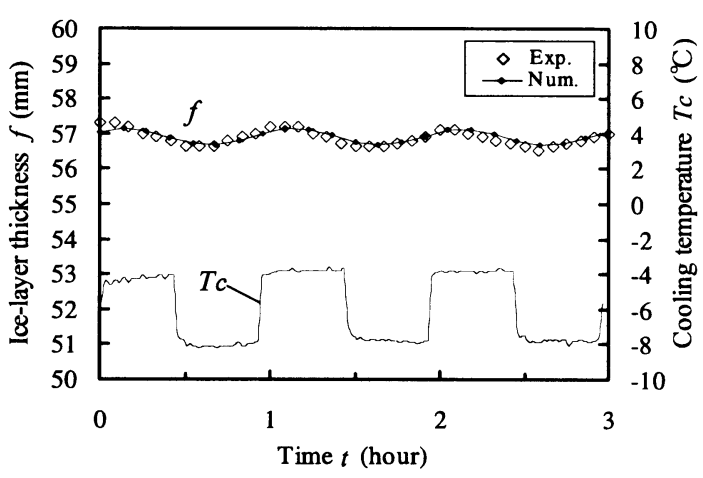

(a) $\bar{T}_{c}=-6^{\circ} \mathrm{C}, P=1 \mathrm{~h}$

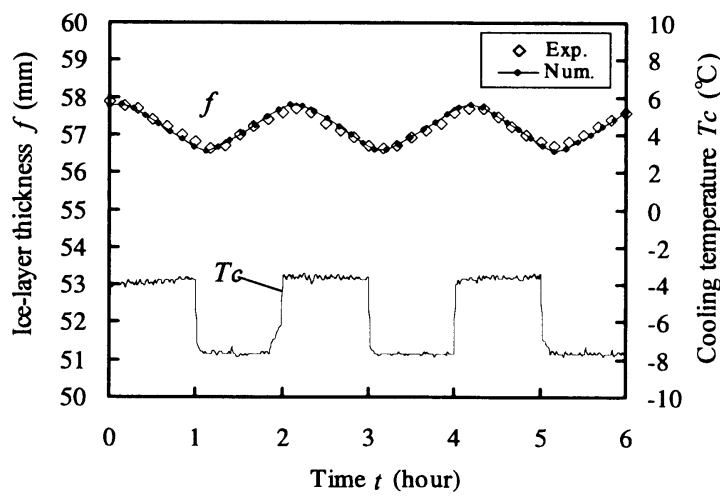

(b) $\bar{T}_{C}=-6^{\circ} \mathrm{C}, P=2 \mathrm{~h}$

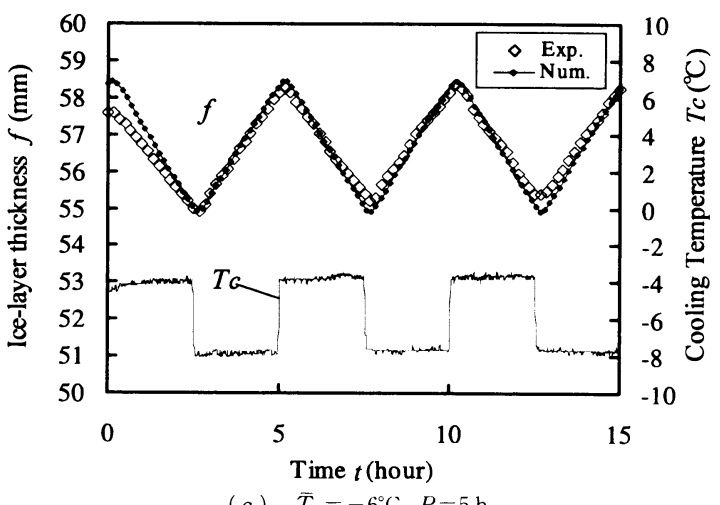

(c) $\bar{T}_{c}=-6^{\circ} \mathrm{C}, P=5 \mathrm{~h}$

Fig. 5 Experimentally measured time-varying cooling temperature and the response of ice-layer thickness. The predicted values of the solid layer thickness by the one-dimensional model are also plotted 


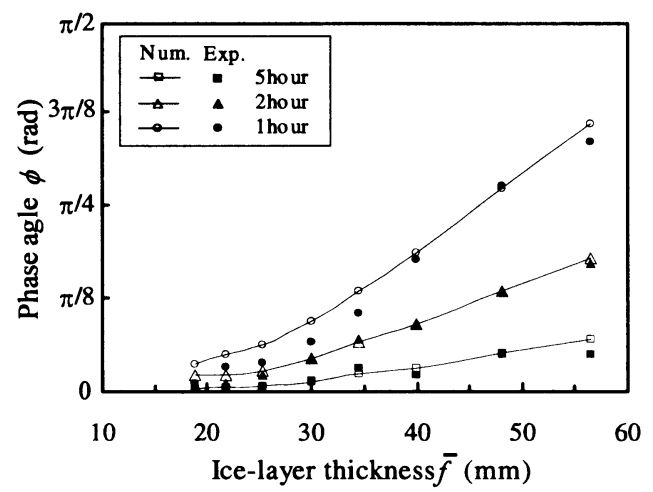

Fig. 6 Phase lag of oscillating ice-layer

次に, 冷却面温度変動の影響を見るために, 冷却面 の平均温度に対して片振幅で $2^{\circ} \mathrm{C}$ 温度変動を与え た. 本研究では冷却面温度について 4 ケース，ビーズ 径について 2 ケース, 温度変動周期について 3 ケース の合計 24 条件の実験および計算を行い, 位相遅れと 界面振動振幅について, 固相厚さや温度変動周期との 関連などを検討した. 例として図 5 に冷却面温度 $T_{C}$ $=-6 \pm 2^{\circ} \mathrm{C}$, 周期 $P=1,2,5 \mathrm{~h}$ で矩形波状に変動させ た 3 ケースについて示す. 固相厚さ $f$ は, 冷却面温度 変動に対して変化するが, 温度変動波形に対して位相 遅れをもって追随している. 図 $5(\mathrm{a})$ の温度変動周期 が小さいほうが界面振動振幅は小さくなっているが, 位相遅れは大きいことがわかる。図 5 中には，一次元 モデルによる数值計算結果を実線で示してある。図 5 に見られるように，計算值と実験值はよく一致してい る.

$5 \cdot 2$ 固液界面変動の位相遅れ 冷却面温度を矩 形波状に変動させた際の固液界面振動の温度波形に対 する位相遅れ $\phi$ を図 6 に示す。位相遅れ $\phi$ は温度が 低下あるいは上昇した時刻と，固相が成長あるいは融 解に転じた時刻の差に基づいている，横軸に定常時の 固相厚さ $f$ を, 緃軸に位相遅れ $\phi$ をとった，位相遅 れは平均固相厚さが減少するにつれ, 温度伝播に要す る時間が小さくなるため減少する。また，温度変動周 期が増大すると，現象が準定常状態に近づくため位相 遅れは減少する. 固相厚さが小さい側の 4 点はビーズ 径が $d=5 \mathrm{~mm}$ の場合であり, 大きい側の 4 点はビー ズ径が $d=2 \mathrm{~mm}$ の場合の実験結果である. $d=5$ $\mathrm{mm}$ の場合は液相内での自然対流が活発であり, 固液 界面への対流熱伝達も大きい. 位相遅れは液相内の対 流状態によらず平均固相厚さの減少，および温度変動 周期の増大に伴い一様に減少している。また，実線で 示した一次元計算の結果は実験とよく一致している.

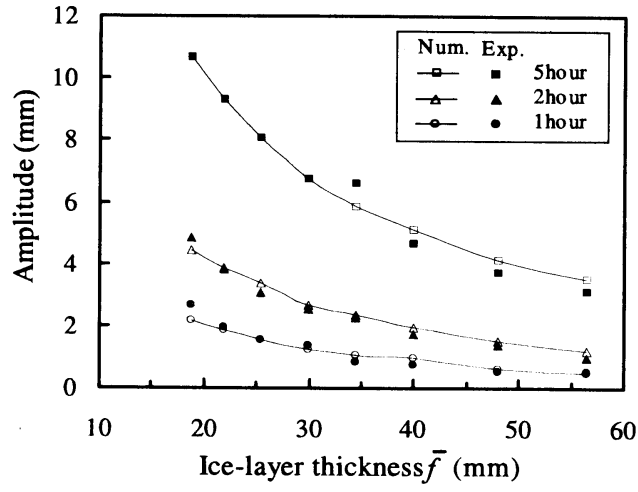

Fig. 7 Overall amplitude of the solid-liquid interface

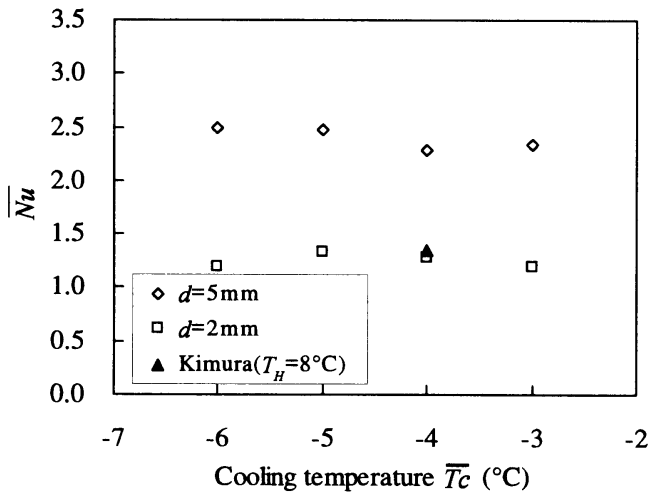

Fig. 8 Average Nusselt numbers obtained from steady state ice-layer thicknesses formed at the top wall

ただ周期 $1 \mathrm{~h}$ の場合は最大 $40 \%$ ほど実験值が小さな 值を示している。これは図 5(a)のように $f(t)$ の振 幅が約 $1 \mathrm{~mm}$ と小さく, しかも山や谷が滑らかになり 精確なピーク位置の判定が困難なためである.

$5 \cdot 3$ 固液界面振動振幅次に, 冷却面温度変動 に対する固液界面振動振幅について述べる. 図 7 に示 すように, 界面振動振幅は温度変動周期の増大ととも に, 固相内での温度変動の減衰が小さくなるため増大 する.また, 平均固相厚さの減少に伴い振動振幅は大 きくなる。これは，一つには固相内部における温度変 動の減衰が小さくなるからであり, 同時に平均の冷却 面温度に対する温度振幅が相対的に大きくなるためで もある，位相遅れの場合と同様に，ビーズ径によらず 平均固相厚さの減少に対し, 振動振幅は一様に大きく なっている. 実験結果と一次元計算結果は, この場合 も良好な一致を示している.

$5 \cdot 4$ 液相内の対流と平均ヌッセルト数 水槽内 液相部における自然対流の平均ヌッセルト数の值を木 


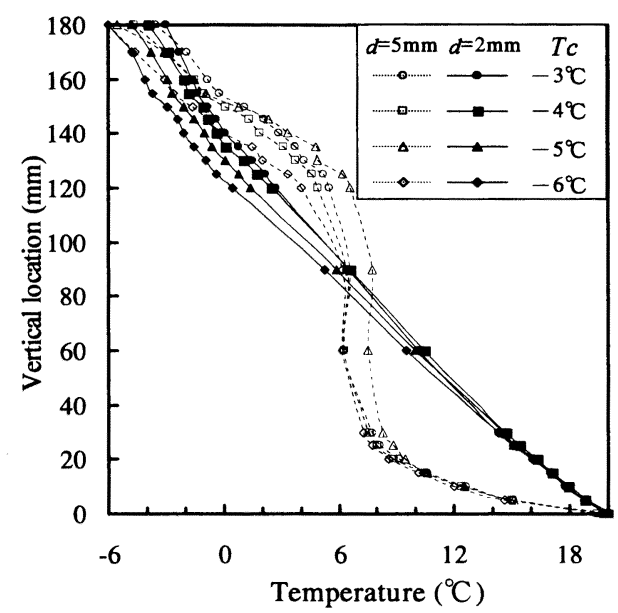

Fig. 9 Vertical temperature distributions in the tank filled with water-saturated glass beads

村ら(11) の自然対流を伴わない場合の值と比較し, 液 相内の対流の影響について考察する. 平均ヌッセルト 数, 修正レイリー数は Blake ら ${ }^{(14)} に$ 従い次式で定義 する.

$$
\begin{aligned}
& \overline{N u}=\frac{q^{\prime \prime}}{k_{e l}\left(T_{H}-T_{0}\right) /(H-\bar{f})} \cdots \\
& R a=\frac{g \beta\left(T_{H}-3.98\right)^{2} K(H-\bar{f})}{\alpha_{e l} v}
\end{aligned}
$$

ここで $\beta$ は温度に対する密度変化を温度の二次関数 として近似した場合の係数で $\beta=8 \times 10^{-6} \mathrm{~K}^{-2}$ の值を 有する。

木村らの実験条件はガラスビーズ径 $d=5 \mathrm{~mm}$, 加 熱面温度は $8^{\circ} \mathrm{C}$, 冷却面温度は $-2^{\circ} \mathrm{C}$ から $-6^{\circ} \mathrm{C}$ でる. 図 8 に定常状態での水層厚さから求めた各冷却面温度 における平均ヌッセルト数の值を示す. 木村らの実験 では冷却面温度の大小にかかわらず, $\overline{N u}$ はほぼ一定 で約 1.3 であった. $\overline{N u}$ が 1 よりもわずかに大きいの は外界から水槽への熱の浸透によるものと推定され た.これに対し, 本研究ではビーズ径 $d=2 \mathrm{~mm}$ の場 合の平均值が $\overline{N u}=1.27$, ビーズ径 $d=5 \mathrm{~mm}$ の場合 の平均値が $\overline{N u}=2.54$ となった. また, 冷却面温度に 対する $\overline{N u}$ の依存性はあまり見られない.これは平 均の冷却面温度変化による平均固相厚さの変動が, 液 相部深さに対して小さいためである. 図 9 にはこのと きの水槽内温度分布を示す. ビーズ径 $d=2 \mathrm{~mm}$ の場 合は温度分布が直線に近く, 対流の効果はほとんど現 れていない.これに対して, $d=5 \mathrm{~mm}$ の場合は水槽 中間部が対流によってかくはんされ, 温度が均一に近 くなっている.
木村ら(11) の実験結果を, Blake ${ }^{(14)} ら の$ 数值計算結 果と比較すると, 実験の場合は, 加熱面温度が $8^{\circ} \mathrm{C} て ゙$ 修正レイリー数はいずれも臨界值 200 以下となり, 対 流が生じていないことがわかる.この場合, 液相部は 熱伝導が支配的となり, 液相からの平均熱流束を一定 と仮定することにより水層の平均厚さの時間的変動を よくとらえることができた。これは氷層の振幅が液相 厚さの $5 \%$ 以下であり, 液相内での鉛直方向温度こう 配があまり変化しないためである。本研究では Blake らの数値計算の適用範囲を超えているため, 直 接の比較はできないが, 特にビーズ径が $5 \mathrm{~mm}$ の場合 に $\overline{N u}$ が大きく, 活発な対流が発生しているのは明ら かである.この場合も一次元数値計算と実験結果はよ く一致することが確認できた.このことから, 液相部 で活発な自然対流が存在する場合でも, 対流熱伝達の 効果を一次元モデルで固液界面での平均熱流束として 表現することにより, 平均水層厚さの動的挙動を記述 することが可能である.一般的に平均熱流束 $q^{\prime \prime}$ の決 定には対流熱伝達の相関式が必要となる。このような 相関式が存在する問題については平均熱流束がただち に計算でき, 提案した一次元計算モデルを適用するこ とにより温度変動周期や温度変動振幅をさまざまに変 化させた場合の平均固層厚さの時間的変動を簡便に計 算することができる.

$$
\text { 6. スケールアナリシス }
$$

ここでは, 冷却面温度が時間的に周期変動するとき, 水層の平均厚さ変動とその位相遅れについてスケール アナリシスに基づき考察する。一様温度を有する半無 限媒体で, 境界温度が時間的に変動する場合の温度場 に関する問題は, よく知られているようにストークス 第 2 問題として解くことができる.いま簡単のため, 冷却面温度が平均温度 $\bar{T}_{c}$ のまわりに温度振幅 $\Delta T_{c}$, 角振動数 $\omega$ で正弦波状に時間変動する場合を想定す

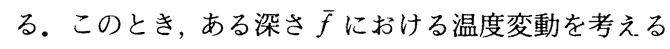
と, その深さにおける温度変動の大きさと位相遅れは, これと同じ平均厚さをもつ氷層の成長と減退, および その位相遅れを支配していると考えられる。すなわ ち, 媒体が有限の厚さをもつ場合でも, 無限媒体中と 同じょうに境界面での温度変動が固液界面まで伝ぱす ると仮定する。したがって, 冷却面からの距離 $\bar{f}$ (平 均水層厚さ)での固液界面の変動幅 $\Delta f$ は, 半無限媒 体中で同じ距離だけ離れている位置での温度変動の大 きさに比例すると考えられる. ストークスの解から次 の比例関係が得られる。 


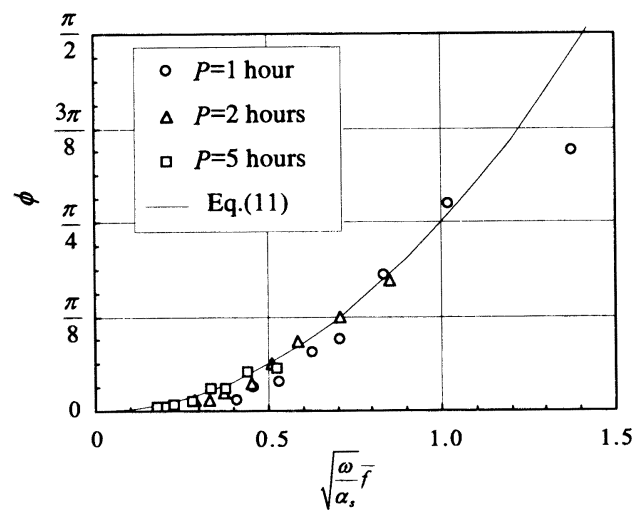

Fig. 10 Phase delay of oscillating solid-liquid boundary against the nondimensional thickness of ice layer

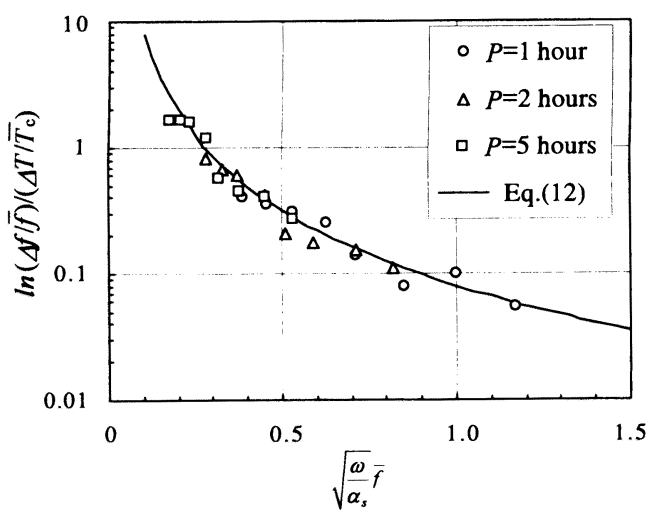

Fig. 11 Nondimensional amplitude of the solid-liquid boundary against the nondimensional thickness of ice layer

$$
\frac{\Delta f}{\bar{f}} \sim \frac{\Delta T_{C}}{\bar{T}_{c}} \exp \left(-\sqrt{\frac{\omega}{2 \alpha_{S}}} \bar{f}\right) \sin \left(\omega t-\sqrt{\frac{\omega}{2 \alpha_{S}}} \bar{f}\right)
$$

これからただちに, 矩形波状に冷却面温度が変動する 場合にも位相差と固液界面の振動振幅はともに無次元 距離 (無次元水層厚さ) $\sqrt{\omega / \alpha_{S}} \bar{f}$ の関数となることがう かがえる.そこで図 6,7 の位相差と界面振幅に関す る実験結果を無次元水層厚さ $\sqrt{\omega / \alpha_{s}} \vec{f}$ の関数として表 すことを試みる.ただし, 固液界面の振動振幅に関し ては式(10) から次の無次元振幅 $\ln \left[(\Delta f / \bar{f}) /\left(\Delta T_{c} / \bar{T}_{c}\right)\right]$ を縦軸にとる。このようにまとめた実験結果は, 図 10 と図 11 に見るようにややばらつきがあるものの, 無 次元水層厚さ $\sqrt{\omega / \alpha_{s}} \bar{f}$ に対して単一の関数として整理 されるのがわかる. 図 10,11中の実線はプロット点 に対するカーブフィットから求めたものである. 本実
験のように, 上方冷却で, 冷却面温度変化に対する固 相厚さの変動振幅が液相深さに比べ十分小さい場合, 位相遅れに対して式(11)，界面の振幅について式(12) がよい近似式である。

$$
\begin{aligned}
& \phi=\frac{\pi}{4}\left(\sqrt{\frac{\omega}{\alpha_{S}}} \bar{f}\right)^{2} \ldots \ldots \ldots \ldots \ldots \ldots \ldots \ldots \ldots \ldots \\
& \ln \left(\frac{\Delta f / \bar{f}}{\Delta T_{c} / \bar{T}_{C}}\right)=0.08\left(\sqrt{\frac{\omega}{\alpha_{S}}} \bar{f}\right)^{-2}
\end{aligned}
$$

\section{7. 結 論}

正方形水槽にガラスビーズと水を満たした飽和多孔 質体の下面を $20^{\circ} \mathrm{C}$ に保持し, 上面を氷点下で冷却し, 冷却面温度を矩形波状に周期変動させた際の凝固・融 解応答特性について調べ, 以下の結果を得た。

（1）冷却面温度変動を与えた際の固液界面位置変 動の振幅は, 平均固相厚さの減少および温度変動周期 の増大とともに大きくなる.

（2）冷却面温度変動に対する固液界面位置変動の 位相遅れは, 平均固相厚さの減少および温度変動周期 の増大に伴い減少する。

（3）固液界面が液相部から受ける対流による平均 熱流束を一定と仮定した一次元数值計算コードを開発 し, 実験との比較を通して, 活発な対流熱伝達を伴う 条件下での, 本計算モデルの有効性を示した.

（4）スケールアナリシスにより, 冷却面温度の周 期的変動に対する固液界面変動の振幅と位相遅れが無 次元固相厚さの関数として整理できることを示した.

\section{文献}

（1）尾添紘之, $\mathrm{Cz}$ 法に扔ける磁場による自然対流の制御，な がれ, 19 (2000), 296-305.

（2）多田幸生・林勇二郎, 生物体凍結における伝熱と紐胞の 生存, 伝熱研究, 37-145 (1998), 13-20.

（3）岡田昌志，ダルシー流中に直交して置かれた二円柱周り の凍結, 冷凍, 54-625 (1979), 891-898.

(4) 岡田昌志, ダルシー流中に直交して置かれた二円柱周り の凍結問題の近似解法, 冷凍, 56-639 (1981), 3-13.

(5) Sugawara, M., Inaba, H. and Seki, N., Effect of Maximum Density of Water on Freezing of a WaterSaturated Horizontal Porous Layer, Trans. ASME, J. Heat Transf., 110 (1988), 155-159.

(6) Sasaki, A., Aiba, S. and Fukusako, S., Numerical Study on Freezing Heat Transfer in Water-Saturated Porous Media, Numer. Heat Transf., Part A, 18 (1990), 17-32.

(7) Viskanta, R. and Beckerman, C., Natural Convection Solid/Liquid Phase Change in Porous Media, Int. J. Heat Mass Transf., 31 (1988), 35-46.

(8) Lock, G. S. H., Gunderson, J. R., Quon, D. and Donnely, J. K., A study of One-Dimensional Ice Formation With Particular Reference to Periodic Growth and Decay, Int. J. Heat Mass Transf., 12 (1969), 1343-1351.

（9）越後亮三・原武志・平田賢, 表面温度が周期的に変化す 
る系の凍結・融解に関する解析, 機論, 68-669（2002）, 1531-1536.

（10）越後亮三・原武志・平田賢, 表面温度が周期的に変化す る系の凍結・融解に関する解析 (続報)，機論， 69-683 (2003), 1673 1678.

（11）木村繁男・岡島厚・木綿隆弘・中村太樹, 上方冷却によ る矩形水槽内での飽和多孔質体の凝固・融解特性, 機論, 69-682, B (2003), 1482-1487.

（12）木村繁男・岡島厚・木綿隆弘・村井孝行，凝固過程の動
的な応答に関する数値解析 (周期的冷却温度変化に対す る固相厚さの応答), 機論, 68-665, B(2002), 175-180).

(13) Saitoh, T., Numerical Method for Multi Dimensional Freezing Problems in Arbitary Domains, Truns. ASME, J. Heat Transf., 100 (1978), 294-299.

(14) Blake, K. R. and Bejan, A., Natural Convection Near $4^{\circ} \mathrm{C}$ in a Water Saturated Porous Layer Heated from Below, Int. J. Heat Mass Transf., 27-12 (1984), 2355 2364 . 